\title{
LARYNGOLOGY
}

\section{Upper dysphagia in patients affected by systemic sclerosis: prevalence and features}

\author{
La disfagia orale e faringea in pazienti affetti da sclerosi sistemica: \\ prevalenza e caratteristiche
}

\begin{abstract}
Jacopo Galli ${ }^{1}$, Maria Raffaella Marchese², Claudia De Canio ${ }^{3}$, Mariachiara Mandiello³, Giuseppe Michele Mangone ${ }^{3}$, Angela Anna Padula ${ }^{4}$, Giuseppina Abignano ${ }^{4}$, Lorenzo Santandrea ${ }^{3}$, Gaetano Paludetti ${ }^{1}$

${ }^{1}$ Department of Aging, Neuroscience, Orthopedics and Head and Neck Sciences, UOC of Otorhinolaryngology, Istituto di Otorinolaringoiatria "Fondazione Policlinico Universitario A. Gemelli IRCCS, Università Cattolica del Sacro Cuore", Roma, Italy; ${ }^{2}$ Department of Aging, Neuroscience, Orthopedics and Head and Neck Sciences, UOC of Otorhinolaryngology, "Fondazione Policlinico Universitario A. Gemelli IRCCS", Roma, Italy; ${ }^{3}$ ENT Department, San Carlo Hospital, Potenza, Italy; ${ }^{4}$ Rheumatology Institute of Lucania (IReL) and Rheumatology Department of Lucania, San Carlo Hospital of Potenza and Madonna delle Grazie Hospital of Matera, Potenza, Italy
\end{abstract}

\begin{abstract}
SUMMARY
Herein, we describe the prevalence and features of dysphagia in patients affected by systemic sclerosis (SS). We analysed the data of 19 patients obtained by administering the M.D. Anderson Dysphagia Inventory (MDADI) scale that measures dysphagia symptoms and by physical assessment consisting of judging specific lip, mandible and tongue performances (scale 0-3) and diadochokinesis, respiratory and phonatory functions (scale "poor", "fair", "good", "normal") according to Robertson's method. Subjects also underwent flexible endoscopic examination of swallowing. MDADI showed that $74 \%$ of answers were included in "mild" class of disability, $21 \%$ as "moderate" and $5 \%$ as "severe". The performance of lips, mandible and tongue that most frequently scored 1 were the opening ( $52.6 \%$ for the lips and $47.4 \%$ for the mandible) and the pop of the tongue $(52.7 \%)$. The percentage of compromised respiratory, phonatory and diadochokinesis tests ("poor" or "fair") was $81 \%, 70.1 \%$ and $74 \%$, respectively. Flexible endoscopic examination of swallowing revealed pharyngolaryngeal sensory deficit and signs of oropharyngeal dysphagia in more than half of cases (58\% and 53\%, respectively). This study highlights the presence of dysphagia in SS patients and demonstrates the importance of a multidimensional approach that includes subjective and objective evaluation to characterise specific features of swallowing alterations that have a high-impact on upper dysphagia.
\end{abstract}

KEY WORDS: dysphagia, systemic sclerosis, upper dysphagia, flexible endoscopic examination of swallowing

\section{RIASSUNTO}

Scopo dello studio è stato quello di valutare, per mezzo di un campionamento trasversale, la prevalenza e le caratteristiche dei disturbi di deglutizione in pazienti affetti da sclerosi sistemica (SS). Abbiamo analizzato i dati ottenuti da 19 pazienti sottoposti a tests soggettivi, clinici e strumentali. Per la valutazione soggettiva è stato utilizzato il questionario di autovalutazione "M.D. Anderson Dysphagia Inventory". Per l'esame clinico ai pazienti veniva chiesto di eseguire specifici movimenti e prassie delle labbra, della lingua e della mandibola (score da 0 a 3), performances vocali, respiratorie e di diadococinesi in accordo con il sistema Robertson's ("insufficiente", "quasi sufficiente", "sufficiente" e "normale"). Infine ciascun paziente veniva sottoposto ad esame fibroendosopico della deglutizione con test della sensibilità. Risultati dell'MDADI: il 74\% dei pazienti mostrava un'alterazione "lieve" della deglutizione, il $21 \%$ ed il $5 \%$ rispettivamente un grado "moderato" e "severo" di disfagia. Le performances più compromesse erano l'apertura della mandibola e delle labbra (52,6\% and 47,4\%) e lo schiocco della lingua (52.7\%). La voce, la respirazione e la diadococinesi erano alterate in più del 70\% dei casi. La FEES ha dimostrato un'alterazione della fase faringea e la presenza di deficit della sensibilità faringolaringea in più della metà dei pazienti (58\% e 53\%). Lo studio mette in evidenza l'elevata prevalenza della disfagia alta nei pazienti affetti da sclerosi sistemica e dimostra l'importanza di una valutazione multidimensionale che coinvolga entrambi il logopedista ed il foniatra in grado di eseguire un esame clinico specifico e strumentale mirato, indispensabili per contribuire a riconoscere la sede della disfagia e con essa caratteristiche non altrimenti rilevabili.

PAROLE CHIAVE: disfagia, sclerosi sistemica, disfagia orale e faringea, valutazione fibroendoscopica della deglutizione
Received: September 18, 2019

Accepted: March 20, 2020

Correspondence

Maria Raffaella Marchese

Department of Aging, Neuroscience, Orthopedics and Head and Neck Sciences, UOC of Otorhinolaryngology, Fondazione Policlinico Universitario A. Gemelli IRCCS

1.go A. Gemelli 8, 00168 Rome, Italy

Tel. +3906 30154439. Fax +39063051194

E-mail: mariaraffaella.marchese@ policlinicogemelli.it

Funding

None.

Conflict of interest

The Authors declare no conflict of interest.

How to cite this article: Galli J, Marchese MR, De Canio C, et al. Upper dysphagia in patients affected by systemic sclerosis: prevalence and features. Acta Otorhinolaryngol Ital 2020;40:204210. https://doi.org/10.14639/0392-100X-N0477

๑ Società Italiana di Otorinolaringoiatria e Chirurgia Cervico-Facciale

\section{(c) (1) $\Theta($}

This is an open access article distributed in accordance with the CC-BY-NC-ND (Creative Commons Attribution-NonCommercial-NoDerivatives 4.0 International) license. The article can be used by giving appropriate credit and mentioning the license, but only for non-commercial purposes and only in the original version. For further information: https:// creativecommons.org/licenses/by-nc-nd/4.0/deed.en 


\section{Introduction}

Systemic sclerosis (SS) is a rare autoimmune disorder characterised by alterations in humoral and cellular immunity, leading to fibroproliferative alterations in microvasculature which in turn causes abnormal collagen deposition in the skin and internal organs ${ }^{1,2}$. The gastrointestinal tract is one of the most commonly affected organ systems, involved in approximately $90 \%$ of SS patients. The specific changes contribute to autonomic dysfunctions and dysmotility ${ }^{4}$ that cause a variety of morbid symptoms including dysphagia ${ }^{2-4}$. The pathogenesis of dysmotility is related to progression of myopathy, neuropathy and fibrosis leading to abnormalities in compliance and contractility of the GI tract wall ${ }^{4}$. In the literature, dysphagia is reported as a rare presenting complaint of scleroderma in which symptoms occur as the oesophagus becomes more severely affected. When the oesophagus is compromised, the disease process is usually diffuse with involvement of multiple levels of the gastrointestinal tract ${ }^{5}$. Nevertheless, as demonstrated in a previous study, dysphagia (oropharyngeal) is actually not so rare in immunomediated diseases, particularly in cases affected by SS ${ }^{6}$. The recent literature offers no specific studies that are capable of ruling out the presence of primary alterations of swallowing in SS. In addition, almost all published studies describe dysphagia in SS as lower or non-specific dysphagia. Up to now, except for a case reported in $1981{ }^{7}$, only Rajapakse et al. ${ }^{8}$ presented a case series affected by dysfunction of the pharyngoesophageal region. Therefore, based on the available literature, oropharyngeal dysphagia (OD) is infrequent, poorly recognised and poorly documented.

It is known that aspiration, pneumonia, malnutrition, increased mortality, prolonged hospitalisation, advanced disability and declining quality of life may be the consequences of OD. Since early dysfunction is still very responsive to appropriate management, it is clear that early diagnosis and treatment are fundamental issues in preventing such lifethreatening complications.

In the light of all the aforementioned considerations, the primary objective of this study was to investigate the prevalence of swallowing dysfunction in SS patients using selfassessment questionnaires in addition to physical evaluation that included clinical and instrumental approaches. The secondary aims were to describe the features of dysphagia focusing on the site and characteristics of symptoms and to provide a detailed description of the structural and functional abnormalities.

\section{Materials and methods}

From January to June 2018, at the clinics and rheumatology department of St. Carlo's Hospital at Potenza, we recruited patients affected by SS disease. The inclusion criterion was clinically and laboratory-defined SS disease. The exclusion criteria were thyroid, laryngeal, oesophageal (all except GERD), gastric, respiratory diseases or previous surgery, inability to cooperate, and past or present swallowing rehabilitation therapy. All patients routinely underwent ENT evaluation including flexible fiberoptic rhinolaryngoscopy to evaluate the anatomical integrity of pharynx and larynx. Comorbidities were recorded and patients were asked to answer specific dysphagia symptoms listed in the dysphagic adults assessment questionnaire developed by Travalca Cupillo-Castellini ${ }^{12}$ (Tab. I). All persons gave their informed consent prior to inclusion in the study.

In order to assess the impact of dysphagia on the quality of life, we selected the "MDADI" M. D. Anderson Dysphagia Inventory translated into Italian ${ }^{9,10}$. It is a long-standing validated screening self-reported measure of a patient's perceived handicap or impairment from their swallowing. We opted for MDADI because of its simplicity, limited number of questions and direct scoring to assess the handicapping effects of OPD. In order to calculate the prevalence of symptoms (items), we divided the answers into two classes: "No symptomatic" that included the "never" and "almost never" answers and "Symptomatic" that included the "almost always" and "always". Moreover, we calculated the total score between 0 and 60 and, to obtain a grading scale of dysphagia, we divided the distribution of the scores into four classes of disability: 0-2 (absent), 3-14 (mild), 15-29 (moderate) and 30-60 (severe). One additional item is present, whose score is not computed in the total of the MDADI score but which accounts for the general (G) distress reaction to symptoms ("Does your swallowing problem interfere with your quality of life?"). The interviews were carried out by two trained speech pathologists (DC, MM). With respect to bedside swallowing evaluation (BSE) ${ }^{11}$, clinical signs closely related to dysphagia and aspiration were considered: presence of "wet voice", postswallow residue in the mouth and post-swallow cough. Moreover, using a scale from 0 (not able) to 3 (good) the performance of the lips, mandible and tongue was tested according to the protocol of Travalca Cupillo-Castellini ${ }^{12}$, and, diadochokinesis, respiratory and phonatory functions according to Robertson's method ${ }^{13}$ (scoring "poor", "fair", "good" and "normal"). Finally, we performed flexible endoscopic examination of swallowing with a sensory test according to Rees ${ }^{14}$ and Langmore ${ }^{15}$. The sensory test was performed by lightly touching the aryepiglottic fold or the tip of the epiglottis with the tip of endoscope and ask the patient if he/she feels it. We considered normal subjects who answered affirmatively or who coughed. 
Table I. Prevalence of swallowing symptoms and comorbidities in decreasing order.

\begin{tabular}{|c|c|c|c|c|c|}
\hline Symptoms & No. cases & $\%$ & Comorbidities & No. cases & $\%$ \\
\hline Food or liquid come back up into the throat & $13 / 19$ & 68 & Sicca syndrome & $9 / 19$ & 47 \\
\hline Frequent throat clearing & $13 / 19$ & 68 & Osteoarthrosis & $8 / 19$ & 42 \\
\hline The amount of saliva is decreased & $12 / 19$ & 63 & Arterial hypertension & $8 / 19$ & 42 \\
\hline Food or liquid come back up into the mouth & $12 / 19$ & 63 & Gastroesophageal reflux disease & $7 / 19$ & 37 \\
\hline Globus pharyngeal & $11 / 19$ & 58 & Sjogren syndrome & $4 / 19$ & 21 \\
\hline Feeling of food remaining in the upper throat & $11 / 19$ & 58 & Hiatal hernia & $4 / 19$ & 21 \\
\hline You clear your throat when you swallow food & $10 / 19$ & 53 & Hypovitaminosis D & $3 / 19$ & 16 \\
\hline Difficulty to start swallowing & $9 / 19$ & 47 & Thyroid nodules & $3 / 19$ & 16 \\
\hline Cough when you swallow food & $8 / 19$ & 42 & Hashimoto's thyroiditis & $3 / 19$ & 16 \\
\hline Feeling of food remaining in the mouth & $8 / 19$ & 42 & Hypothyroidism & $3 / 19$ & 16 \\
\hline Loss of saliva during the night & $6 / 19$ & 32 & Pulmonary arterial hypertension & $3 / 19$ & 16 \\
\hline Decrease in body weight & $6 / 19$ & 32 & Osteoporosis & $3 / 19$ & 16 \\
\hline History of pneumonia by bacterial infection & $6 / 19$ & 32 & Dyslipidaemia & $2 / 19$ & 11 \\
\hline Feeling of food in the lower throat & $5 / 19$ & 26 & Venous chronic insufficiency & $2 / 19$ & 11 \\
\hline The amount of saliva is increased & $4 / 19$ & 21 & Esophagitis & $1 / 19$ & 5 \\
\hline Increase in body weight & $4 / 19$ & 21 & Hypercholesterolaemia & $1 / 19$ & 5 \\
\hline Leakage of food or fluid from the mouth & $3 / 19$ & 16 & Diabetes type 2 & $1 / 19$ & 5 \\
\hline Food or liquid come back up into the nose & $3 / 19$ & 16 & & & \\
\hline
\end{tabular}

Written informed consent was obtained from all participants included in the study. Statistical analysis was performed using commercially available software (Excel - Microsoft Corporation, Redmond, Washington, USA). Continuously distributed outcomes were summarised as means and categorical outcomes with frequencies and percentages. The numerical data and categoric variables were compared by applying a Student's t test and chi-square test, respectively. The level of significance was set at $\mathrm{p}<0.05$.

\section{Results}

From a series of 28 patients, 9/28 met exclusion criteria and 19/28 were considered. Seventeen cases were female and two were males with a mean age of 58.9 years (min. 30 max 78; SD = 13.5). Three of $19(16 \%)$ casess were affected by diffuse cutaneous SS and 16/19 (84\%) by limited cutaneous SS.

\section{Comorbidities and dysphagia-specific symptoms}

The principal comorbidities and respective prevalence are listed in Table I. Sicca syndrome was the most prevalent occurring in $9 / 19$ (47\%) of cases, followed by osteoarthritis $8 / 19(42 \%)$, arterial hypertension $(8 / 19 ; 42 \%)$, gastro-oesophageal reflux $(7 / 19 ; 37 \%)$ and fibromyalgia $(5 / 19 ; 26 \%)$. The prevalence of specific dysphagia symptoms is shown in Table I. The symptoms referred by more than half of cases were "Frequent throat clearing" (13/19; 68\%), "Food or liquid come back up into the throat" (13/19; 68\%), "Food or liquid come back up into the mouth" (12/19; 63\%), "The amount of saliva is decreased" (12/19; 63\%), "Feeling of food remaining in the upper throat" (11/19; 58\%), "You clear your throat when you swallow food" $(10 / 19 ; 53 \%)$.

\section{M.D. Anderson Dysphagia Inventory (MDADI)}

The total mean score was 11.42 ("mild" dysphagia). In particular, $74 \%$ of answers were included in "mild" class of disability, $21 \%$ as "moderate" and $5 \%$ as "severe". The partial scores for each group of questions were 7.68, 2.42 and 1.31 for the Physical, Emotional and Functional sections, respectively. The score of the Physical $(\mathrm{P})$ section was the highest and significantly greater compared with the other sections $(\mathrm{p}<0.05)$. Finally, the mean score of Emotional (E) sub-items was significantly higher than the Functional $(\mathrm{F})$ one $(\mathrm{p}<0.05)$. The mean percentage of "Symptomatic" answers was $17.58 \%, 10.53 \%$ and $6.32 \%$ for P, E and $\mathrm{F}$ group of sub-items, respectively. Nevertheless, these frequencies were significantly less $(\mathrm{p}<0.05)$ compared with those of answers with a score between 0-1 (82.42\%, $89.47 \%, 93.68 \%$ and for the physical, emotional and functional group of sub-items respectively). Table II showed the frequency of all items in decreasing order. Regarding the item for general $(\mathrm{G})$ distress reaction to dysphagia, 26.3\% of answers were included as "Symptomatic".

\section{Bedside swallowing evaluation}

The tongue appeared atrophic in 17/19 (89\%) of patients, while they were normal in the remaining two cases. On- 
ly $2 / 19(10 \%)$ patients had normal teeth, while the other 17 patients (89\%), partially or totally edentulous, used dental prostheses. Three of 19 (16\%) patients showed a "wet voice", while post-swallow residue in the mouth was observed in $12 / 19(63 \%)$ of cases and in only $1 / 19(5.2 \%)$ case was post-swallow cough present. As shown in Table III the performance of the lips most frequently scoring as 1 was the opening $(52.6 \%)$. The remaining dynamic tests of the lips were performed almost normally (score 2 ) in the more than half of cases $(54.7 \%)$. The opening of mandible and the pop of the tongue were most frequently compromised since a score of 1 was present in $47.4 \%$ of patients and in $52.7 \%$, respectively. The percentage of compromised respiratory tests ("poor" or "fair") was $81 \%$ and significantly higher compared with "good" or "normal" performances $(18.9 \%)(\mathrm{p}<0.05)$. The test most frequently judged "poor" was "take a deep breath, then make the /s/ sound again, but start at a whisper then get louder". The frequencies of the remaining tests are showed in Table IV; $70.1 \%$ of phonatory performances were abnormal ("poor" and "fair") and $29.8 \%$ were "good" or "normal". The difference was statistically significant $(\mathrm{p}<0.05)$. The first two recurrent tests with "poor" score were, respectively, "Take a deep breath and during expiration say /a/ how long is possible" and
"Take a deep breath and say a sustained /al as soft and as loud possible". Finally, 76.3\% of diadochokinesis tests were impaired ("poor" and "fair"). In particular, $74 \%$ of performances were "fair" (Tab. IV).

\section{Flexible endoscopic examination of swallowing}

The findings of flexible endoscopic examination are shown in Table V. The oral phase lasted a mean of 21.8 seconds (SD 5.5).

\section{Discussion}

Among musculoskeletal diseases, dysphagia is best known as a complication of scleroderma. Nevertheless, the literature refers almost exclusively to the dysfunction caused by the oesophageal abnormalities ${ }^{16}$. In reality, the SS has numerous deleterious effects that compromise more than one stage of the swallowing process. Salivary dysfunction can be seen in up to half of patients with SS as demonstrated by Baron et al. ${ }^{17}$. Consistent with the literature, we observed the co-occurrence of Sicca syndrome in $47 \%$ of cases and 63\% complained of a sensation of "dry mouth". Microstomia (decrease of the mouth opening) and microcheilia (decrease of the lip opening) are common manifes-

Table II. Mean prevalence of MDADI items with score $>1$ in decreasing order.

\begin{tabular}{|c|c|c|}
\hline \multirow{2}{*}{\multicolumn{2}{|c|}{ Physical }} & \multirow[t]{2}{*}{ Prevalence (\%) } \\
\hline & & \\
\hline P7 & It takes me longer to eat because of my swallowing problem & 42 \\
\hline P4 & I feel that I am swallowing a huge amount of food & 26.3 \\
\hline P5 & I limit my food intake because of my swallowing difficulty & 26.3 \\
\hline P6 & Swallowing takes great effort & 21 \\
\hline P8 & I cough when I try to drink liquids & 21 \\
\hline P2 & Swallowing is more difficult at the end of the day & 15.8 \\
\hline P3 & People ask me, "Why can't you eat that?" & 15.8 \\
\hline P1 & I cannot maintain my weight because of my swallowing problems & 10.5 \\
\hline \multicolumn{3}{|c|}{ Functional } \\
\hline F5 & My swallowing difficulty has caused me to lose income & 15.8 \\
\hline $\mathrm{F} 2$ & I feel free to go out to eat with my friends, neighbors, and relatives & 10.5 \\
\hline F3 & My swallowing problems limit my social and personal life & 5.3 \\
\hline $\mathrm{F} 1$ & People have difficulty cooking for me & 0 \\
\hline F4 & I feel excluded because of my eating habits & 0 \\
\hline \multicolumn{3}{|c|}{ Emotional } \\
\hline E4 & I am upset by my swallowing problem & 26.3 \\
\hline E7 & I do not feel self-conscious when I eat & 15.8 \\
\hline E6 & I have low self-esteem because of my swallowing problems & 10.5 \\
\hline E2 & I am embarrassed by my eating habits & 5.3 \\
\hline E3 & Other people are irritated by my eating problem & 5.3 \\
\hline E5 & I do not go out because of my swallowing problem & 0 \\
\hline
\end{tabular}


tations of SS that are reported to be present in 50-80\% of cases ${ }^{18-20}$. Specifically, we observed microstomia in $47 \%$ of subjects. Erosions and resorption of mandible and temporomandibular joint involvement are common findings among SS patients and may explain the previously mentioned changes ${ }^{21}$. Overall, reduced oral opening and xerostomia interfere with speech, mastication and oral hygiene predisposing to oral and dental disease. In this regard, it is

Table III. Prevalence of score 0, 1, 2 and 3 for performance of the lip, mandible and tongue.

\begin{tabular}{|c|c|c|c|c|}
\hline & 0 & 1 & 2 & 3 \\
\hline \multicolumn{5}{|l|}{ Lips } \\
\hline Opening & - & $52.7 \%$ & $36.8 \%$ & 10.5 \\
\hline Extension & $5.3 \%$ & $26.3 \%$ & $57.9 \%$ & 10.5 \\
\hline Protrusion & - & $31.6 \%$ & $57.9 \%$ & 10.5 \\
\hline Ability to hold a depressor between the lips & - & $10.5 \%$ & $68.5 \%$ & 21 \\
\hline Exert force against resistance & $5.3 \%$ & $26.3 \%$ & $52.7 \%$ & 15.7 \\
\hline \multicolumn{5}{|l|}{ Mandible } \\
\hline Opening & - & $47.4 \%$ & $42.1 \%$ & $10.5 \%$ \\
\hline Lateralisation & $5.3 \%$ & $36.8 \%$ & $36.8 \%$ & $21.1 \%$ \\
\hline Protrusion & $5.3 \%$ & $36.8 \%$ & $47.4 \%$ & $10.5 \%$ \\
\hline \multicolumn{5}{|l|}{ Tongue } \\
\hline Protrusion & - & $15.8 \%$ & $57.9 \%$ & $26.3 \%$ \\
\hline Lateralisation & - & $15.8 \%$ & $57.9 \%$ & $26.3 \%$ \\
\hline Tongue tip elevation out of the mouth & $31.5 \%$ & $26.3 \%$ & $36.9 \%$ & $5.3 \%$ \\
\hline Tongue tip elevation into the mouth & $10.5 \%$ & $26.3 \%$ & $52.7 \%$ & $10.5 \%$ \\
\hline Circular movements around the lips & - & $15.8 \%$ & $63.2 \%$ & $21 \%$ \\
\hline Pop of the tongue & $21 \%$ & $52.7 \%$ & $10.5 \%$ & $15.8 \%$ \\
\hline Vertical resistance & $36.8 \%$ & $36.8 \%$ & $26.3 \%$ & - \\
\hline Lateral resistance & $5.2 \%$ & $26.3 \%$ & $47.4 \%$ & $21.1 \%$ \\
\hline Central resistance & - & $15.8 \%$ & $42.1 \%$ & $42.1 \%$ \\
\hline
\end{tabular}

Table IV. Distribution of respiratory, phonatory and diadochokinesis performance.

\begin{tabular}{|c|c|c|c|c|}
\hline & Poor & Fair & Good & Normal \\
\hline \multicolumn{5}{|l|}{ Respiratory } \\
\hline Take a deep breath, then make the /s/ sound for as long as you can & $42.1 \%$ & $37 \%$ & 0 & $21.1 \%$ \\
\hline Take a deep breath, then make the /s/ sound again, but start at a whisper then get softer & $52.7 \%$ & $42.1 \%$ & 0 & $5.2 \%$ \\
\hline After a deep breath say repeatedly /s/ & $47.3 \%$ & $37 \%$ & $10.5 \%$ & $5.2 \%$ \\
\hline Take a deep breath, then make the /a/ sound for as long as you can. & $42.1 \%$ & $36.8 \%$ & $15.8 \%$ & $5.3 \%$ \\
\hline Take a deep breath, then make the /a/ sound for as aloud as you can. & $26.3 \%$ & $36.8 \%$ & $26.3 \%$ & $10.5 \%$ \\
\hline Begin at your conversational level of speech, say /a/ and sing up a scale & $36.8 \%$ & $47.4 \%$ & $10.5 \%$ & $5.3 \%$ \\
\hline Begin at your conversational level of speech, say /a/ and sing down a scale & $42.1 \%$ & $36.8 \%$ & $10.5 \%$ & $10.5 \%$ \\
\hline Protrude and retract lips as many times as you can in 5 seconds & $31.6 \%$ & $63.1 \%$ & $5.3 \%$ & 0 \\
\hline Protrude and retract tongue as many times as you can in 5 seconds & $82.4 \%$ & $10.5 \%$ & $5.3 \%$ & 0 \\
\hline Raise and lower the tongue as many times as you can in 5 seconds & $94.7 \%$ & $5.3 \%$ & 0 & 0 \\
\hline Move tongue from side to side as many times as you can in 5 seconds & $89.4 \%$ & $5.3 \%$ & 0 & $5.3 \%$ \\
\hline
\end{tabular}


Table V. Percentage endoscopic of fiberoptic evaluation of swallowing findings.

\begin{tabular}{lcc} 
Findings & N. cases & $\%$ \\
1. Laryngopharyngeal sensory deficit & 11 & 58 \\
2. Repeated dry swallows & 10 & 53 \\
3. Residue post-swallow & 10 & 53 \\
4. Mucous secretions in the pharynx and larynx & 5 & 26 \\
5. Facilitating manoeuvres & 5 & 26 \\
6. Dryness appearance of oropharyngeal mucosa & 5 & 26 \\
7. Deficit of oral bolus propulsion & 4 & 21 \\
8. Glottic incompetence & 3 & 16 \\
9. Delayed swallow initiation & 2 & 11 \\
10. Abnormal pharyngeal squeeze & 2 & 11 \\
11. Aspiration or penetration pre-, intra-, post-swallow & 0 & 0 \\
\hline
\end{tabular}

interesting to note that almost all our cases were edentulous and showed atrophic tongues.

Our results were not differentiated based on the stage of the disease. Nevertheless, the percentage of subjective swallow abnormalities resulted from the anamnestic list of symptoms was higher: dysphagia was present in $40-50 \%$ of cases and was mostly related to oral and oropharyngeal dysphagia. Among all symptoms, globus pharyngeal was reported in $58 \%$ of the sample versus $5-45 \%$ estimated in the general population, respectively, for persistent and intermittent globus pharyngeal ${ }^{22,23}$. We hypothesise that the prevalence increases in SS patients because of disease-related xerostomia, pharmacotherapy and other less well-understood processes involving immune-mediated mucosal changes and altered sensory perception. In our sample, the symptoms (i.e. "feeling of food remaining in the mouth" and "feeling of food remaining in the lower throat", "difficulty to start swallowing") are consistent with objective findings. First, the BSE showed post-swallowing oral residue, and, moreover, flexible endoscopic examination revealed dry swallows and post-swallow pharyngo-layngeal residue in $53 \%$ of cases and deficit of oral bolus propulsion in $21 \%$. Similarly, Montesi et al. ${ }^{7}$ found abnormalities in the oral and pharyngeal phases during videofluoroscopy (VFS) in SS patients. Using VFS, Russo et al. ${ }^{24}$ demonstrated the presence of intraswallowing laryngeal penetration caused by altered epiglottal motility in $57.8 \%$, and pooling of contrast agent in the valleculae and/or pyriform sinuses in $51.1 \%$. Nevertheless, it cannot be excluded that upper esophageal sphincter dysfunction is possible in SS or secondary to GERD which may cause this finding.

Gastro-oesophageal reflux (GERD) occurs in over $50 \%$ of SS patients, which causes symptoms mimicking swallowing disorder. In our sample, $37 \%$ of patients had a diagnosis of GERD and almost $70 \%$ complained of symptoms sug- gestive of GERD (raclage, sensation of food backing up into the throat or mouth). Thonhofer et al. ${ }^{25}$ found a high prevalence of oesophageal disease in asymptomatic patients. However, further research specifically oriented to clarify the role of GERD on dysphagia in SS is necessary. Forty-two percent of cases reported onset of cough during swallowing and one-third of patients had had at least one episode of pneumonia by bacterial infection. This may be correlated to the multifactorial increased risk of aspiration in SS. First, we found "poor" or "fair" performances of respiratory, phonatory and diadochokinesis in about $80 \%$ of patients. Normally, eating, swallowing and breathing are tightly coordinated; the coordination of breathing and swallowing reveals a well-timed pattern between physiological respiratory events and related swallowing events, and vocal fold closure might be part of a protective mechanism that involves swallowing apnoea ${ }^{26}$. Secondly, it is known that the physiologic breathing cycle is not simply repressed during swallowing; it is substituted by a different and well-controlled behaviour pattern ${ }^{27}$ that is sensitive to variations in bolus volume ${ }^{28-30}$ and viscosity ${ }^{31,32}$. Moreover, direct stimulation of the laryngeal vestibule produces a reflex apnoea with abrupt vocal fold closure. In about $60 \%$ of SS patients, we demonstrated a decrease of laryngeal mechanosensitivity, probably resulting from GERD ${ }^{33}$ that impairs the perception of bolus characteristics, which may consequently alter these mechanisms of control and increase the risk of aspiration. Thirdly, decreased pharyngeal muscular performance as demonstrated by the high percentage (53\%) of dry swallows and pharyngo-laryngeal residue contribute to a further increase of the risk of post-swallow aspiration. Nevertheless, the absence of signs of aspiration or penetration was probably because the residual strength was sufficient to ensure good control of the bolus.

Although swallowing alterations are common in the immunomediated population ${ }^{6}$, as seen herein, they are often overlooked by patients as well (general distress was clinically significant in $26.3 \%$ of cases with a mean "mild" impact) probably because of the predominance of other discomforts. Nevertheless, both early diagnosis and treatment of swallowing alterations is an issue that must be considered carefully. Towards this objective, it is important to evaluate the scores from questionnaires not in absolute terms, but in relation to the clinical background. Moreover, the risk in underestimating dysphagia may be reduced by associating physical and instrumental assessment to characterise the abnormalities in the oral and pharyngeal stages of swallowing ${ }^{34}$.

In conclusion, this study is the first to highlight the importance of a multidimensional approach in swallowing evaluation in SS patients, which should include subjective and objective evaluation (the latter by a speech pathologist and phoniatric consultant). It also demonstrates specific features 
of swallowing alterations to consider when addressing the high impact of the upper dysphagia in SS.

Several limitations should be considered when interpreting this investigation. In addition to the cross-sectional nature of the study, a control group is also lacking. In this regard, this work should be seen as preliminary, but can increase awareness in taking an otorhinolaryngologic approach to dysphagia within the complex framework in patients with SS. It can also encourage ENT specialists and rheumatologists to consider oropharyngeal dysphagia in the evaluation of patients suffering from SS.

\section{References}

1 Guy YS, Kong J, Cheema GS, et al. The immunobiology of systemic sclerosis. Semin Arthritis Rheum 2008;38:132-60. https://doi.org/10.1016/j. semarthrit.2007.10.010

2 Thoua NM, Bunce C, Brough G, et al. Assessment of gastrointestinal symptoms in patients with systemic sclerosis in a UK tertiary referral center. Rheumatology 2010;49:1770-5. https://doi.org/10.1093/rheumatology/keq147

3 Sjogren RW. Gastrointestinal motility disorders in scleroderma. Arthritis Rheum 1994;37:1265-82. https://doi.org/10.1002/art.1780370902

4 Sallam H, McNearney TA, Chen JD. Systematic review: pathophysiology and management of gastrointestinal dysmotility in systemic sclerosis (scleroderma). Aliment Pharmacol Ther 2006;23:691-712. https://doi. org/10.1111/j.1365-2036.2006.02804.x

5 Sheehan NJ. Dysphagia and other manifestations of oesophageal involvement in the musculoskeletal diseases. Rheumatology 2008;47:746-52. https://doi.org/10.1093/rheumatology/ken029

6 Galli J, Marchese MR, De Canio C, et al. The prevalence of dysphonia and dysphagia in patients affected by immunomediated diseases and the role of psychometric tests. Clin Rheumatol 2019;38:77-84. https:// https://doi.org/10.1007/s10067-018-4129-8

7 Montesi A, Pesaresi A, Cavalli ML, et al. Oropharyngeal and esophageal function in scleroderma. Dysphagia 1991;6:219-23. https://doi. org/10.1007/BF02493531

8 Rajapakse C. Pharyngoesophageal dysphagia: an under recognised, potentially fatal, but very treatable feature of systemic sclerosis. Intern Med J 2016;46:1340-4. https://doi.org/10.1111/imj.13243

9 Chen AY, Frankowski R, Bishop-Leone J, et al. The development and validation of a dysphagia-specific quality-of-life questionnaire for patients with head and neck cancer: the M.D. Anderson dysphagia inventory. Arch Otolaryngol Head Neck Surg 2001;127:870-6.

10 Schindler A, Borghi E, Tiddia C, et al. Adaptation and validation of the Italian MD Anderson Dysphagia Inventory (MDADI). Rev Laryngol Otol Rhinol (Bord) 2008;129:97-100.

11 Speyer R. Oropharyngeal dysphagia screening and assessment. Otolaryngol Clin North Am 2013;46:989-1008. https://doi.org/10.1016/j. otc.2013.08.004

12 Travalca Cupillo B, Castellini P. Scheda di valutazione foniatrica logopedica del paziente disfagico adulto. In: Schindler O, Ruoppolo G, Schindler A, editors. Deglutologia. Torino: Omega; 2011.

13 Robertson SJ. Dysarthria profile. Bicester, Oxon: Winslow Press; 1982.

14 Rees CJ. Flexible endoscopic evaluation of swallowing with sensory testing. Current Opin Otolaryngol Head Neck Surg 2006;14:425-30. https:// doi.org/10.1097/MOO.0b013e328010ba88

15 Langmore SE, Schatz K, Olsen N. Fiberoptic endoscopic examination of swallowing safety: a new procedure. Dysphagia 1988;2:216-9. https:// doi.org/10.1007/BF02414429
16 Denton CP, Khanna D. Systemic sclerosis. Lancet 2017;390:1685-99. https://doi.org/10.1016/S0140-6736(17)30933-9

17 Baron M, Hudson M, Tatibouet S, et al. The Canadian systemic sclerosis oral health study: orofacial manifestations and oral health-related quality of life in systemic sclerosis compared with the general population. Rheumatology 2014;53:1386-94. https://doi.org/10.1093/rheumatology/ ket 441

18 Bajraktari IH, Kryeziu A, Sherifi F, et al. Oral manifestations of systemic sclerosis and correlation with anti- topoisomerase I antibodies (SCL-70). Med Arch 2015;69:153-6. https://doi.org/10.5455/medarh.2015.69.153-156

19 Crincoli V, Fatone L, Fanelli M, et al. Orofacial manifestations and temporomandibular disorders of systemic scleroderma: an observational study. Int J Mol Sci 2016;17:E1189. https://doi.org/10.3390/ijms17071189

20 Jung S, Martin T. The spectrum of orofacial manifestations in systemic sclerosis: a challenging management. Oral Dis 2017;23:424-39. https:// doi.org/10.1111/odi.12507

21 Dagenais M, MacDonald D, Baron M, et al. The Canadian Systemic Sclerosis Oral Health Study IV: oral radiographic manifestations in systemic sclerosis compared with the general population. Oral Surg Oral Med Oral Pathol Oral Radiol 2015;120:104-11. https://doi.org/10.1016/j.00oo.2015.03.002

22 Deary IJ, Wilson JA, Kelly SW. Globus pharyngis, personality, and psychological distress in the general population. Psychosomatics 1995;36:570-7. https://doi.org/10.1016/S0033-3182(95)71614-0

23 Thompson WG, Heaton KW. Heartburn and globus in healthy people. Can Med Assoc J 1982;126:46-8.

24 Russo S, Lo Re G, Galia M, et al. Videofluorography swallow study of patients with systemic sclerosis. Radiol Med 2009;114:948-99. https:// doi.org/10.1007/s11547-009-0416-4

25 Thonhofer R, Siegel C, Trummer M, et al. Early endoscopy in systemic sclerosis without gastrointestinal symptoms. Rheumatol Int 2012;32:1658. https://doi.org/10.1007/s00296-010-1595-y

26 Nishino T. Interaction of swallowing and control of breathing. Nihon Kyobu Shikkan Gakkai Zasshi 1990;28:16-21.

27 Selley WG, Flack FC, Ellis R, et al. Respiratory pattern associated with swallowing: Part 1. The normal adult pattern and changes with age. Age Ageing 1989;18:168-72. https://doi.org/10.1093/ageing/18.3.168

28 Butler SG, Postma GN, Fischer E. Effects of viscosity, taste and bolus volume on swallowing apnea duration of normal adults. Otolaryngol Head Neck Surg 2004;131:860-3. https://doi.org/10.1016/j.otohns.2004.06.706

29 Martin BJ, Logemann JA, Shaker R, et al. Coordination between respiration and swallowing: respiratory phase relationships and temporal integration. J Appl Physiol 1994;76:714-23. https://doi.org/10.1152/ jappl.1994.76.2.714

30 Nordio S, Di Stadio A, Koch I, et al. The correlation between pharyngeal residue, penetration/aspiration and nutritional modality: a cross-sectional study in patients with neurogenic dysphagia. Acta Otorhinolaryngol Ital 2020;40:38-43. https://doi.org/10.14639/0392-100X-2136

31 Carnaby-Mann G, Crary M. Pill swallowing by adults with dysphagia. Arch Otolaryngol Head Neck Surg 2005;131:970-5. https://doi. org/10.1001/archotol.131.11.970

32 Hiss SG, Strauss M, Treole K, et al. Effects of age, gender, bolus volume, bolus viscosity and gustation on swallowing apnea onset relative to lingual bolus propulsion onset in normal adults. J Speech Lang Hear Res 2004;47:572-83. https://doi.org/10.1044/1092-4388(2004/044)

33 Phua S, McGarvey L, Ngu M, et al. Patients with gastro-oesophageal reflux disease and cough have impaired laryngopharyngeal mechanosensitivity. Thorax 2005;60:488-91. https://doi.org/10.1136/thx.2004.033894

34 Farneti D, Fattori B, Bastiani L. Time as a factor during endoscopic assessment of swallowing: relevance in defining the score and severity of swallowing disorders. Acta Otorhinolaryngol Ital 2019;39:2449. https://doi.org/10.14639/0392-100X-N0221 